\title{
Accelerated Gas-liquid Visible Light Photoredox Catalysis with Continuous-Flow Photochemical Microreactors
}

\author{
Natan J. W. Straathof, ${ }^{a, \dagger}$ Yuanhai Su, ${ }^{a, \dagger}$ Volker Hessel, ${ }^{a}$ Timothy Noël ${ }^{a, b *}$ \\ a Eindhoven University of Technology, Department of Chemical Engineering and Chemistry, Micro \\ Flow Chemistry \& Process Technology, Building 14 (Helix), De Rondom 70, 5612 AP Eindhoven, The \\ Netherlands. \\ ${ }^{\mathrm{b}}$ Department of Organic Chemistry, Ghent University, Krijgslaan 281 (S4), 9000 Ghent, Belgium. \\ ${ }^{\dagger}$ Authors contributed equally to this work. \\ Correspondence should be addressed to T.N. (T.Noel@tue.nl)
}

\begin{abstract}
In this protocol, a detailed description for the construction and application of an operationally simple photochemical microreactor for visible light gas-liquid photoredox catalysis is presented. The general procedure includes details of an appropriate photochemical setup and representative procedures for the continuousflow preparation of trifluoromethylated heterocycles and thiols, and disulfides via generation of singlet oxygen. The reported photomicroreactors are modular, inexpensive and can be prepared rapidly from commercially available parts within one hour even by non-specialists. Interestingly, typical reaction times of gas-liquid visible light photocatalytic reactions can be reduced from the hour range in batch to the minute range in microflow. This can be attributed to the improved irradiation efficiency of the reaction mixture and the enhanced gas-liquid mass transfer in the segmented gas-liquid flow regime.
\end{abstract}


Keywords: Photoredox Catalysis, Continuous Flow, Microreactor, Trifluoromethylation, Photocatalytic Oxidation. 


\section{Introduction}

Recently, visible light photoredox catalysis has emerged as a new and innovative approach to enable small molecule activation. This activation mode relies on the use of organometallic complexes ${ }^{1}$ or organic dyes ${ }^{2,3}$ to absorb photons and to, subsequently, engage in single electron or energy transfer processes with organic substrates (Figure 1). Due to the generally mild reaction conditions and the use of low energy visible light as an abundant and perennial energy source, photoredox catalysis has received an increasing amount of attention and allows for unprecedented reaction pathways in high yield and selectivity.

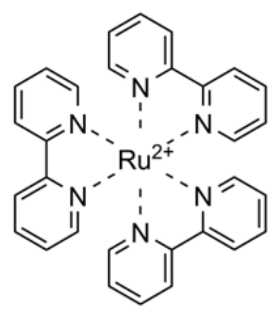

$\left[\mathrm{Ru}(\mathrm{bpy})_{3}\right]^{2+}$

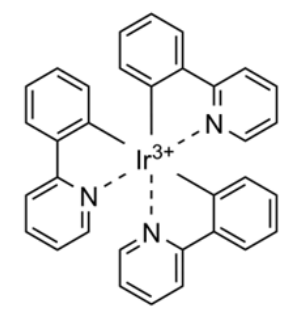

fac-Ir(ppy) $)_{3}$

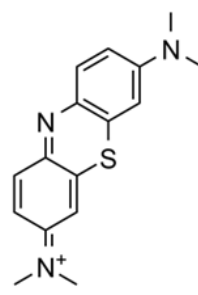

Methylene Blue

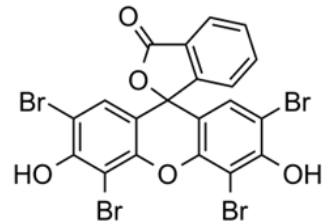

Eosin $Y$

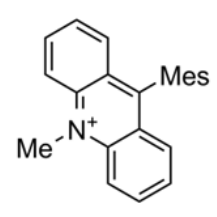

Fukuzumi Salt

Figure | 1. Representative photocatalysts used in visible light photoredox catalysis.

However, some inherent limitations are associated with the use of conventional batch reactors to enable photochemical transformations. One limitation is derived from the attenuation effect of photon transport, which prevents scale up of photochemistry in batch reactors (Lambert-Beer law). Herein, photons are completely absorbed in the outer rim of the reactor, while the center of the reactor receives no light. Consequently, scaling of photochemistry cannot be achieved by simply increasing the dimensions of the reactor design. ${ }^{4-5}$ Another limitation is the use of gaseous reactants in conjunction with batch reactors, which result in poorly defined interfacial contact areas between the gas and the liquid phase. Due to the 
difficult handling of gases in batch, such reactants are often avoided by synthetic chemists in research laboratories.

In the last decade, the use of continuous-flow microreactors for both photochemical and gas-liquid reactions has gained considerable amounts of attention as it allows for a high degree of control over various reaction parameters ${ }^{6-7}$. Due to the small dimensions of microreactors, a homogeneous irradiation of the entire reaction medium can be achieved which allows for shorter reaction/residence times, higher reaction selectivity and lower catalyst loadings ${ }^{8-9}$. Moreover, carrying out gas-liquid reactions in microreactors results in a segmented flow regime (Taylor flow) providing enhanced mixing, increased radial mass transfer and minimal axial dispersion ${ }^{10-13}$.

Here, we report a detailed protocol for the construction and application of a gasliquid photochemical microreactor starting from commercially available parts. The reactor assembly is next demonstrated in the photocatalytic trifluoromethylation of heterocycles ${ }^{14-15}$ and thiols ${ }^{16}$ using cheap $\mathrm{CF}_{3}$ l gas, and in the photocatalytic aerobic oxidation of thiols to prepare disulfides using oxygen gas (Figure 2$)^{17-18}$. The protocols provide a safe, reproducible and scalable alternative for the traditional batch scale methods.
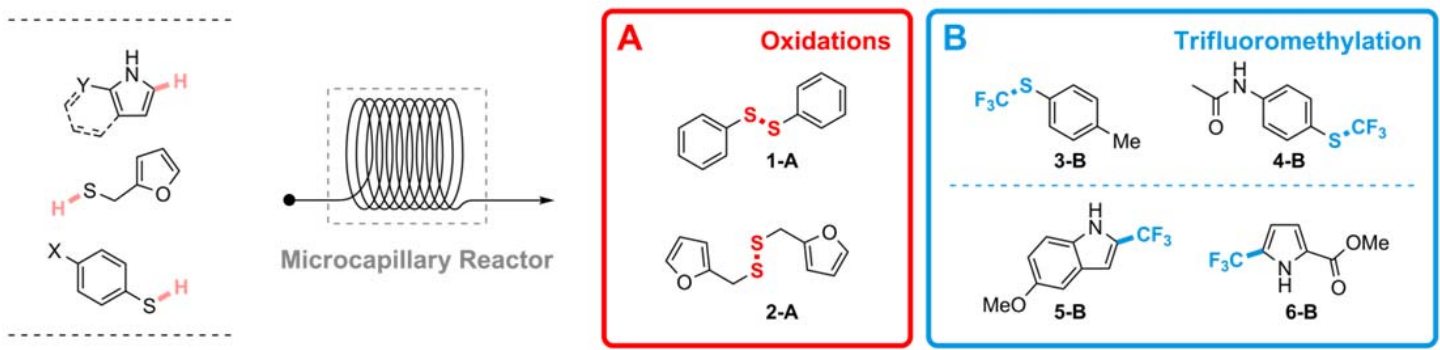

Figure 2 | Overview of the compounds prepared with the photomicroreactor setup. Typical aerobic oxidation conditions (compounds 1-A and 2-A): Thiol, TMEDA (2 equiv.), Eosin Y (5 mol\%), Ethanol, 
Oxygen, White LED. Typical trifluoromethylation conditions (compounds 3-B-6-B): Heterocycle or thiol, TEA or TMEDA (2 equiv.), $\mathrm{Ru}(\mathrm{bpy}){ }_{3} \mathrm{Cl}_{2} \cdot 6 \mathrm{H}_{2} \mathrm{O}$ (1 mol\%), $\mathrm{CF}_{3} \mathrm{I}$ (1.2 equiv.), MeCN, Blue LED.

\section{Overview of this protocol}

We describe the construction of a compact photomicroreactor which is broadly applicable in wide variety of visible light photocatalytic reactions. The design is compact and simple but, nevertheless, highly innovative as it obeys to fundamental chemical and engineering principles. In this protocol, we have specifically focused on gas-liquid photocatalytic reactions since such reaction conditions pose particular technological challenges to synthetic chemistry. However, the design delineated in this protocol is highly modular allowing it to serve as a benchmark example for other photochemical applications. With minor changes, it can easily be extended to other photocatalytic or photochemical protocols, e.g. homogeneous photocatalysis or UV mediated photochemistry ${ }^{19-20}$.

While excellent commercial systems do exist, our protocol allows researchers to rapidly implement the technology in their laboratories as it is simple to assemble, inexpensive in construction and flexible in design, which allows to tailor the reactor to specific requirements. In addition, variation of reaction conditions and parameters (reaction times, gas and liquid flow rates, reagent and catalyst loadings, etc.) can be rapidly achieved without reengineering the design.

In Figure 3, a schematic overview is given of the gas-liquid photomicroreactor setup. The microreactor is constructed using high purity perfluoroalkoxyalkane (PFA) capillary tubing ( $0.75 \mathrm{~mm}$ ID, $1 / 16$ " OD, $1.1 \mathrm{~mL}$ volume) and is coiled around a disposable plastic syringe coated with refractive aluminum tape. An array of light- 
emitting diodes is wrapped around the reactor and the whole assembly is fixated in a larger diameter disposable plastic syringe. The gas flow rate is monitored and controlled by a mass flow controller (MFC). The liquid flow rate is controlled by syringe pumps. All reactants are mixed in a cross micromixer and the segmented gas-liquid flow is introduced in the photomicroreactor. The reaction can be diluted or quenched upon exiting the photomicroreactor, allowing to control precisely the reaction times.

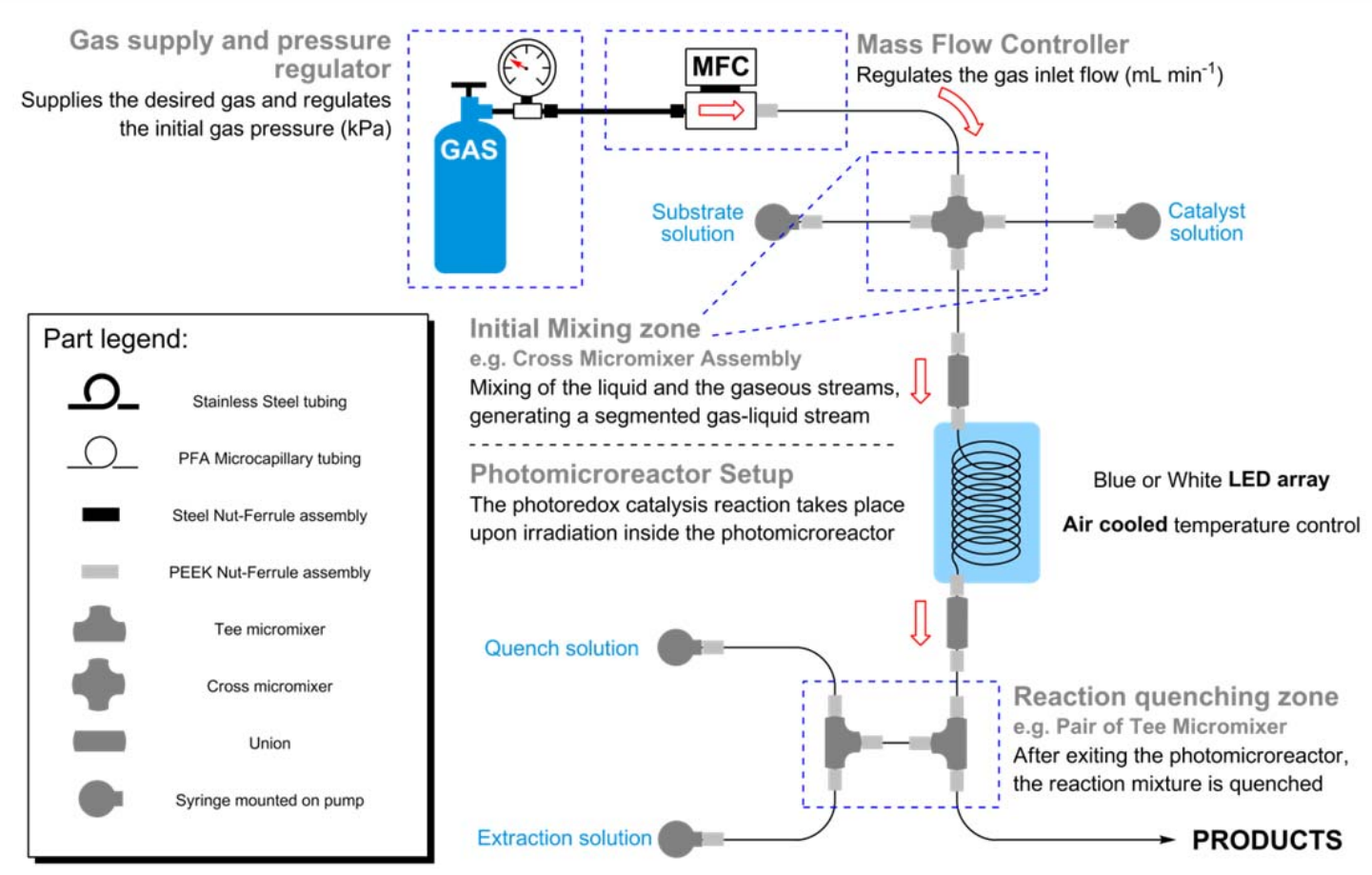

Figure 3 | Schematic overview of a typical continuous-flow photomicroreactor setup for gas-liquid photocatalytic transformations, containing (i) Gas supply and pressure regulator (e.g. trifluoroiodomethane gas or oxygen gas); (ii) Mass flow controller (MFC) assembly to regulate the gas flow ( $\mathrm{mL} \mathrm{min}^{-1}$ ); (iii) Mixing zone before entering the photomicroreactor using a cross micromixer; (iv) Photomicroreactor - an assembly of a coiled PFA capillary microreactor with a LED array as light source; (v) Reaction quenching zone. 


\section{MATERIALS}

\section{Reagents}

<Caution> All chemicals should be handled carefully and with proper personal protection (lab coat, chemical resistant gloves and safety goggles). All procedures should take place inside a fume hood; special care should be taken when handling volatile compounds/reagents. Solid and liquid chemical waste products should be disposed of appropriately, as defined by the local and institutional regulations. Solvents used for the preparation of the compounds are purchased in anhydrous form and used as received. Anhydrous solvents are handled using standard Schlenk techniques, hereby replacing the liquid volume by inert gas (argon). Solvents used for the purification of the compounds are of reagent quality and do not need to be anhydrous.

$<$ Caution $>$ Extreme care should be taken when handling gaseous reagents such as trifluoroiodomethane or oxygen gas. As these gases are colourless and odourless, extra care should be taken to check for possible gas leaks during and after constructing the reaction setup.

- $\quad$ Acetonitrile (Sigma-Aldrich, cat. no. 271004).

- $\quad$ Ethanol (VWR International, cat. no. 20816.367) <Caution> Ethanol is volatile and flammable.

- $\quad$ Ethyl acetate (Biosolve, cat. no. 05400502) <Caution> Ethyl acetate is volatile and flammable.

- $\quad$ Petroleum Ether (PE, Biosolve, cat. no. 17150202) <Caution> PE is volatile and extremely flammable. 
- $\quad$ Acetone (Sigma-Aldrich, cat. no. 34850) <Caution> Acetone is volatile and flammable.

- Thiophenol (Sigma-Aldrich, cat. No. 240249) <Caution> Thiophenol is a volatile and extremely smelly compound. Handle with care and inside the fume hood.

- 4-acetamidothiophenol (Sigma-Aldrich, cat. no. A8201)

- 4-mercaptotoluene (Sigma-Aldrich, cat no. T28525)

- 2-furanmethanethiol (Sigma-Aldrich, cat. no. F20408) <Caution> 2Furanmethanethiol is a volatile and a smelly compound.

- $\quad$ Ethyl 1H-pyrrole-2-carboxylate (Sigma-Aldrich, cat. no. CDS000975)

- 5-Methoxyindole (Sigma-Aldrich, cat. no. M14900)

- $\alpha, \alpha, \alpha-$-trifluorotoluene (Sigma-Aldrich, cat. no. 547948) <Caution> a,a,atrifluorotoluene is a volatile compound.

- $\quad \mathrm{N}, \mathrm{N}, \mathrm{N}^{\prime}, \mathrm{N}^{\prime}$-tetramethylethane-1,2-diamine (Sigma-Aldrich, cat. no. T22500) $<$ Caution $>N, N, N^{\prime}, N^{\prime}$-tetramethylethane-1,2-diamine is irritating and corrosive.

- Triethylamine (Sigma-Aldrich, cat. no. T0886) <Caution> Triethylamine is irritating and corrosive.

- $\quad$ Eosin Y (Sigma-Aldrich, cat. no. 230251).

- $\mathrm{Ru}(\mathrm{bpy})_{3} \mathrm{Cl}_{2} 6 \mathrm{H}_{2} \mathrm{O}$ (Sigma-Aldrich, cat. no. 224758).

- Trifluoroiodomethane (Fluorochem, cat. no. 001461) <Caution> Trifluoroiodomethane is a gaseous reagent and is delivered from a 5 bar pressurized bottle.

- Demineralized water (produced with a Millipore Water Purification system).

- Ammonium Chloride (Sigma-Aldrich, cat. no. A9434) 
- $\quad$ Sodium Bicarbonate (Sigma-Aldrich, cat. no. S5761)

- $\quad 37 \%$ Hydrogen Chloride (Sigma-Aldrich, cat. no. 258148) <Caution> Hydrogen chloride is highly corrosive and very dangerous; handle with care and use proper personal protection.

- $\quad$ Sodium Chloride (Sigma-Aldrich, cat. no. S7653).

- $\quad$ Magnesium Sulfate (Sigma-Aldrich, cat. no. M7506).

- Kieselgel 60 for silica gel column chromatography (Fluka, 230-400 mesh, cat. no. 80148$)<$ Caution> Inhalation and contact with silica dust should be avoided by working in a fume hood and wearing proper personal protection.

- Thin-layer chromatography (TLC) plates (silica gel matrix with aluminum support; Sigma-Aldrich, cat. no. Z193275) <Caution> Do not inhale dust and avoid contact with skin and eyes. 


\section{Equipment}

- Perfluoroalkoxyalkane (PFA) tubing, ID = $0.75 \mathrm{~mm}\left(1 / 16^{\prime \prime} \times 0.030^{\prime \prime} \times 50^{\prime}\right.$, IDEX Health \& Science, Part no. 1632L)

- $\quad$ PFA tubing, ID $=0.50 \mathrm{~mm}\left(1 / 16^{\prime \prime} \times 0.020^{\prime \prime} \times 50^{\prime}\right.$, IDEX Health \& Science, Part no. $1622 \mathrm{~L})$

- $\quad$ PFA tubing ID $=0.25 \mathrm{~mm}\left(1 / 16^{\prime \prime} \times 0.010^{\prime \prime} \times 50^{\prime}\right.$, IDEX Health \& Science, Part no. 1902L)

- Ethylene tetrafluoroethylene (ETFE) Super Flangeless Ferrules (1/16", IDEX Health \& Science, Part no. P-259X)

- $\quad$ Polyether ether ketone (PEEK) Super Flangeless Nut (1/16", IDEX Health \& Science, Part no. LT-115X)

- $\quad$ Polymer Tubing Cutter (IDEX Health \& Science, Part no. A-327)

- $\quad$ Extender torque wrench (IDEX Health \& Science, Part no. P-291)

- $\quad$ PEEK Union (1/16", IDEX Health \& Science, Part no. P-702)

- $\quad$ PEEK Tee micromixer (1/16", IDEX Health \& Science, Part no. P-714)

- $\quad$ PEEK Cross micromixer (1/16", IDEX Health \& Science, Part no. P-722)

- $\quad$ PEEK Quick Connect Luer Adapters (IDEX Health \& Science, Part no. P-658)

- $\quad$ PEEK Shut-off valve (1/16", IDEX Health \& Science, Part no. P-732)

- Inlet Check Valve (15 psi, IDEX Health \& Science, Part no. CV-3301 or CV3320)

- $\quad$ Pressure regulator (0-50 psi, Sigma Aldrich, cat. no. 23883)

- $\quad$ Stainless Steel Seamless Tubing (1/8", Swagelok, Part no. SS-T2-S-035-6ME)

- $\quad$ Stainless Steel Nut (1/8", Swagelok, Part no. SS-202-1)

- $\quad$ Stainless Steel Front Ferrules (1/8", Swagelok, Part no. SS-203-1) 
- $\quad$ Stainless Steel Back Ferrules (1/8", Swagelok, Part no. SS-204-1)

- Stainless Steel Tube adapter (1/4-28 threads to $1 / 8$ ", Valco Instruments Company Inc., Part no. CTA2S6)

- $\quad$ Light-emitting Diode (LED) Power supply (15W, 230 to 12V, Paulmann Lighting GmbH, Part no. 701.99)

- $\quad$ Blue LED array (3.12 W, Paulmann Lighting GmbH, Part no. 702.11)

- White LED array (3.12 W, Paulmann Lighting GmbH, Part no. 703.18)

- Griffon Aluminum Tape High Temperature Roll $50 \mathrm{~m}$ x 5 cm (Part no. 6300096)

- Teflon tape (VWR International, cat. no. 300054)

- $\quad$ BD Plastic Disposable Syringe $5 \mathrm{~mL}$ (VWR International)

- $\quad$ BD Plastic Disposable Syringe $10 \mathrm{~mL}$ (VWR International)

- $\quad$ BD Plastic Disposable Syringe $20 \mathrm{~mL}$ (VWR International)

- $\quad$ BD Plastic Disposable Syringe $50 \mathrm{~mL}$ (VWR International)

- Digital Mass Flow Controller (calibrated for $\mathrm{CF}_{3} \mathrm{l}$ ) (Kalrez Sealing's and Plunger, Bronkhorst Nederland B.V., Part no. F-201CV-020-AAD-11-K, 4 bar inlet, 1-2 bar outlet) $<$ CRITICAL STEP > make sure the MFC is fitted with a Kalrez O-ring sealing and plunger, to prevent swelling of the parts by the $\mathrm{CF}_{3} \mathrm{I}$ gas or solvent fumes.

- Digital Mass Flow Controller (calibrated for $\mathrm{O}_{2}$ ) (Bronkhorst Nederland B.V., Part no. F-200CV-002-AAD-22-K, 7 bar inlet, 3 bar outlet) <CRITICAL STEP> It is important that the MFC is calibrated for pure oxygen since other MFC, including those for air, have lubricants which are flammable in combination with pure oxygen. 
- Display Mass Flow Controller (Bright R/C module, Bronkhorst Nederland B.V., Part no. 7.09.200)

- $\quad$ Power Adapter Mass Flow Controller (Bronkhorst Nederland B.V., Part no. 7.03.422)

- $\quad$ Syringe Pumps (Fusion 200 Touch, KR Analytical Ltd)

- Vacuum Supply (vacuum is generated by a Vacuubrand RZ 6 pump)

- $\quad$ Argon Supply (Purity $\geq 99.99 \%$, through Schlenk Line)

- $\quad$ Oxygen source (Purity $\geq 99.99 \%$ )

- $\quad$ GC-MS (Shimadzu GC-2010 Plus and Shimadzu GCMS-QP 2010 Ultra)

- $\quad$ NMR (Bruker Avance 400, $400 \mathrm{MHz}$ )

- $\quad$ IR (Shimadzu, MIRacle 10 ATR) 


\section{Equipment Setup}

Photomicroreactor and microfluidic connections. For optimal safety and flexibility, the reactor setup is always constructed and operated inside a clean and empty fume hood. The photomicroreactor and microfluidic connections to the pumps and gas bottles are constructed from commercially available microfluidic parts and tubing as depicted in Figure 4-A. Consult Box 1 for the construction of the general photomicroreactor. Consult Box 2 for the construction of the complete microfluidic setup for either the photocatalytic trifluoromethylation reaction or the aerobic oxidation reaction.
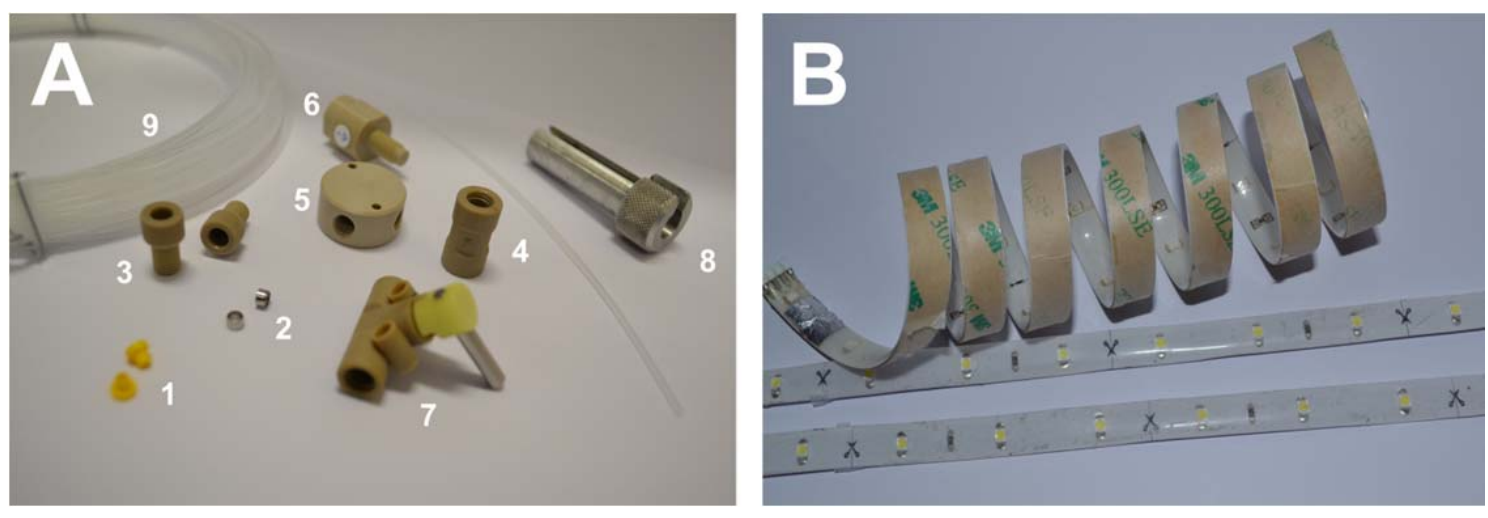

Figure 4 | (A) 1: ETFE ferrules, 2: stainless steel rings, 3: PEEK nut, 4: PEEK straight union, 5: PEEK cross micromixer, 6: Check valve, 7: PEEK shut-off valve, 8: Extender torque wrench, 9: PFA tubing. (B) LED strips (top: coiled; bottom: elongated).

LED Arrays. Light-emitting diode (LED) strips are used as visible light sources (Figure 4-B). The width and length of these LED strips are $1.05 \mathrm{~cm}$ and $97.5 \mathrm{~cm}$, respectively. The number of LED pillars along each strip is 39. Light source 1 (white LED) is used for the photocatalytic oxidation of thiols to disulfides, light source 2 (blue LED) is applied for the photocatalytic trifluoromethylations of pyrroles, indoles 
and thiols. <CRITICAL STEP> Emission spectral characteristics of the light sources should match the absorption profiles, and more specifically the absorption maximum, of the chosen photocatalyst. We advise that every new light source is first characterized by measuring its emission profile. This can be achieved by using an integrating sphere equipped with a Labsphere LPS 100-0260 light detector array, which can measure the spectral emission flux. Absorption spectra of catalyst solutions can be measured via an UV-VIS spectrophotometer (see Supporting Information for emission spectra of the used LEDs in this protocol).

Capillaries I tubing. Transparent capillaries (IDEX Health and Science) of high purity perfluoroalkoxyalkane (PFA) are used to construct the microreactors. They have a high light transmission of $91-96 \%$ for visible light $(\lambda=400-700 \mathrm{~nm})$. The outer and inner diameters of this capillary are $1.58 \mathrm{~mm}(1 / 16 \mathrm{inch})$ and $0.75 \mathrm{~mm}(0.03$ inch), respectively. For example, a length of 2.5 m PFA tubing will give a total inner volume of $1.1 \mathrm{~mL}$. <CRITICAL STEP> The calculation of the capillary volume $\left(\mathrm{V}_{\mathrm{c}}\right)$ can be conducted based on equation 1 (where ID is the inner diameter of the capillary, $L$ is the capillary length).

$$
V_{c}=\pi\left(\frac{I D}{2}\right)^{2} L
$$

Residence times in gas-liquid flow. The actual residence time in reactive gasliquid flows is affected by the pressure drop $(\Delta p)$ over the capillary and the gas consumption. A first rough approximation for the residence time utilizes equation 2 , 
in which $V_{c}$ is the volume of capillary microreactor, $Q_{G}$ and $Q_{L}$ are the inlet volumetric flow rates of the gas and the liquid phase at atmospheric pressure.

$$
t=\frac{V_{c}}{Q_{G}+Q_{L}}
$$

A higher degree of accuracy can be obtained by including the pressure drop and gas consumption. Hereto, we direct the reader to the relevant references in literature ${ }^{18,21}$.

In the case of $\mathrm{CF}_{3} \mathrm{l}$, special care should be taken. This gas is rapidly absorbed by the liquid streams due to a high mass transfer coefficient and high solubility of the gas (especially in the presence of an organic base such as TMEDA or TEA). The actual residence time of the reactants in the microreactor can be calculated with a modified equation (3) in which $f$ is a correction factor for the volumetric gas flow rate which can be determined experimentally. For $\mathrm{CF}_{3}$ l, the value of $f$ is determined to be 0.02 .

$$
t=\frac{V_{c}}{Q_{L}+f \times Q_{G}}
$$

Residence times can be correctly measured experimentally via residence time distribution measurements. ${ }^{22}$ 
Box 1: Construction of the PFA capillary photomicroreactor. $\langle T\|M\| N G\rangle \pm 30$ minutes

1 Wrap aluminum tape around a $20 \mathrm{~mL}$ BD plastic disposable syringe (Figure 5A). <CRITICAL STEP> This action allows to refract the non-absorbed photons back to the transparent microreactor and thus to improve the overall efficiency of the reactor setup.

2 | Cut 2.5 meter of PFA capillary tubing (1/16", ID $=0.75 \mathrm{~mm}, 1.10 \mathrm{~mL}$ volume) with a polymer tubing cutter and wrap it around the refractive tape coated syringe in a spiral fashion (Figure 5-A). <CRITICAL STEP $>$ The volume of the microreactor will determine the flow velocity $\left(\mathrm{m} \mathrm{min}^{-1}\right)$, required flow rate $(\mathrm{mL}$ $\min ^{-1}$ ) and thus throughput (mmol $\min ^{-1}$ ) for a given residence time (min). Importantly, the flow rate is directly related to the mass transfer characteristics; the higher the flow rate, the more intense the mixing will be in the liquid segments, which results in shorter reaction times.

3 | Drill two small holes at the end of a larger diameter BD plastic disposable syringe (100 mL) (Figure 6), which can fit the $20 \mathrm{~mL}$ syringe (wrapped with the PFA capillary microreactor) (Figure 5-C). One hole is used to fixate the smaller diameter syringe by penetrating the nozzle of the latter through the hole (Figure 6). Through the other hole, the outlet of the capillary microreactor is pushed (Figure 6).

4 Coat the inner wall of the larger diameter BD plastic disposable syringe (100 $\mathrm{mL}$ ) with aluminum tape. $<$ CRITICAL STEP> This action allows to refract the non-absorbed photons back to the transparent microreactor and thus to improve the overall efficiency of the reactor setup. 
5 Coil the LED array so that it fits the larger diameter BD plastic disposable syringe $(100 \mathrm{~mL})$ (Figure 5-C). <CRITICAL STEP> Make sure that the emission profile of the LED array matches the intended photocatalytic process.

6 | Place the syringe wrapped with the capillary microreactor inside the larger diameter BD plastic disposable syringe (100 mL) (Figure 5-C). Fix the nozzle of the syringe through the drilled hole (Figure 6).

7 Connect the ends of the PFA capillary tubing with PEEK nuts and ETFE ferrules (Figures 4 and 8). Use an extender torque wrench to make sure the stainless steel rings are pushed completely over the ferrules. <CRITICAL STEP> Do not overtighten the ferrules as this can be a source of gas leakage and solvent spills.

<PAUSE POINT > The photomicroreactor is now completed and ready to be connected to the syringe pump and gas bottle (Box 2). Analogous to this protocol, a series of different reactor assemblies can be constructed, optionally, with different capillaries (e.g. different internal diameter, volume, etc.) or LED light sources (e.g. one can make a UV photomicroreactor using UV LEDs) ${ }^{19-20}$. The same photomicroreactor can be used as well for homogeneous photocatalytic reaction conditions.
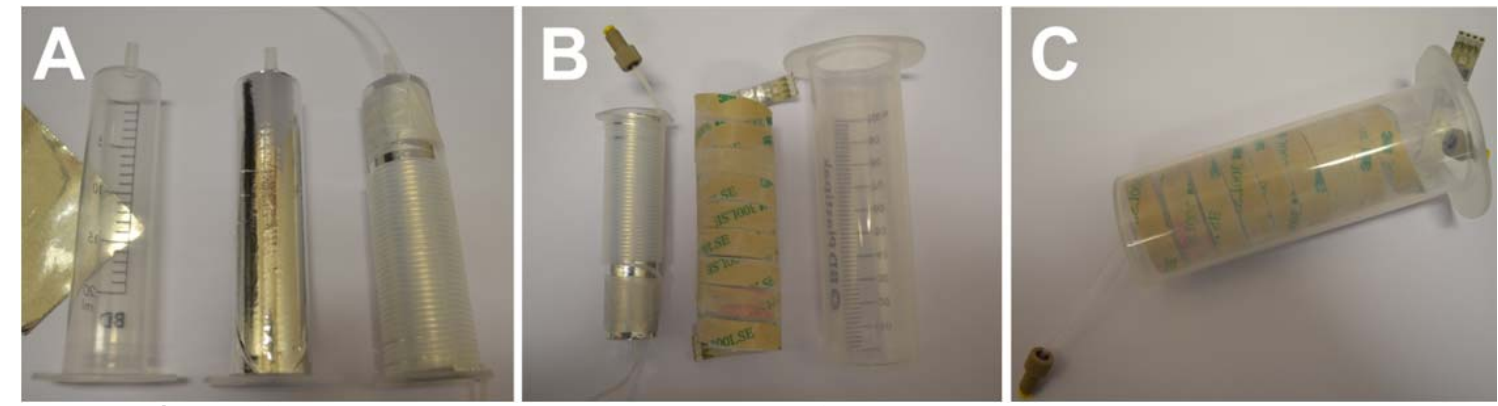

Figure 5 | (A) refractive tape around a $20 \mathrm{~mL}$ syringe, followed by the PFA microtubing coiled around 
the syringe (microreactor), (B) large syringe as LED placeholder, (C) LED array and microreactor positioned inside the placeholder (finished photomicroreactor).
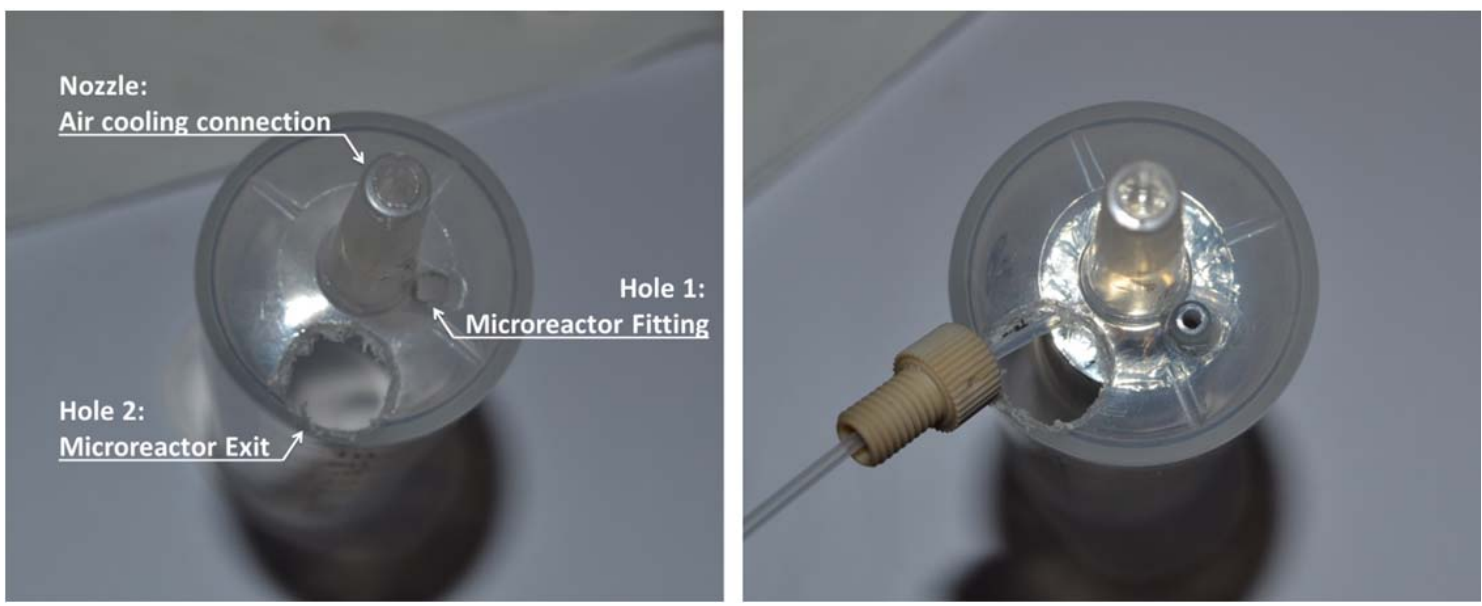

Figure 6 | Drilled holes in the larger diameter syringe used to fixate the photomicroreactor and to fit the exit of the microreactor. The nozzle is used to provide air cooling.

Mass Flow Controller (MFC). The mass flow controller is assembled according to the supplier's instructions (Figure 7). Note that the MFC instrument should always be turned on 30-60 minutes before use. This ensures a correct working of the MFC according to the suppliers specifications. <CRITICAL STEP> In literature, there are many examples which do not use a MFC to introduce a gas phase in a microreactor. In such cases, often an inexpensive needle valve is used to reduce the gas pressure and to tune the gas/liquid ratio. However, we recommend to always use a MFC to ensure reproducible results, to know the exact reaction stoichiometry and to facilitate the startup of the experiments. <CRITICAL STEP> After use, we recommend to purge the MFC with a flow of argon or nitrogen gas (e.g. set the gas flow rate to 1 $\left.\mathrm{mL} \mathrm{min}^{-1}\right)$. This ensures that the residual gas and/or solvent fumes are properly 
removed. We also recommend to disconnect the MFC from the photomicroreactor to avoid diffusion of solvent fumes, which might lead to malfunctioning of the MFC.

\section{Box 2: Assembly of the complete microfluidic setup for photocatalytic} gas/liquid reactions. $<T I M I N G> \pm 45 \mathrm{~min}$

1| Fit a pressure regulator on the trifluoroiodomethane gas bottle or on the oxygen supply.

2 Connect the inlet of the mass flow controller (MFC) to the pressure regulator using standard $1 / 8$ " stainless steel fittings and connectors (Figure 7A).

3 Connect the outlet of the MFC to a stainless steel tube adaptor (1/8" to $\left.1 / 16^{\prime \prime}\right)$ (Figure 7B).

4 Check the gas inlet system (steps 1-3) for any gas leakages. This can be done by submerging the connections in soap water and checking if bubbles are formed. <CAUTION> Both $\mathrm{CF}_{3} \mathrm{I}$ and $\mathrm{O}_{2}$ are colourless, odourless and hazardous. <TROUBLE SHOOTING>
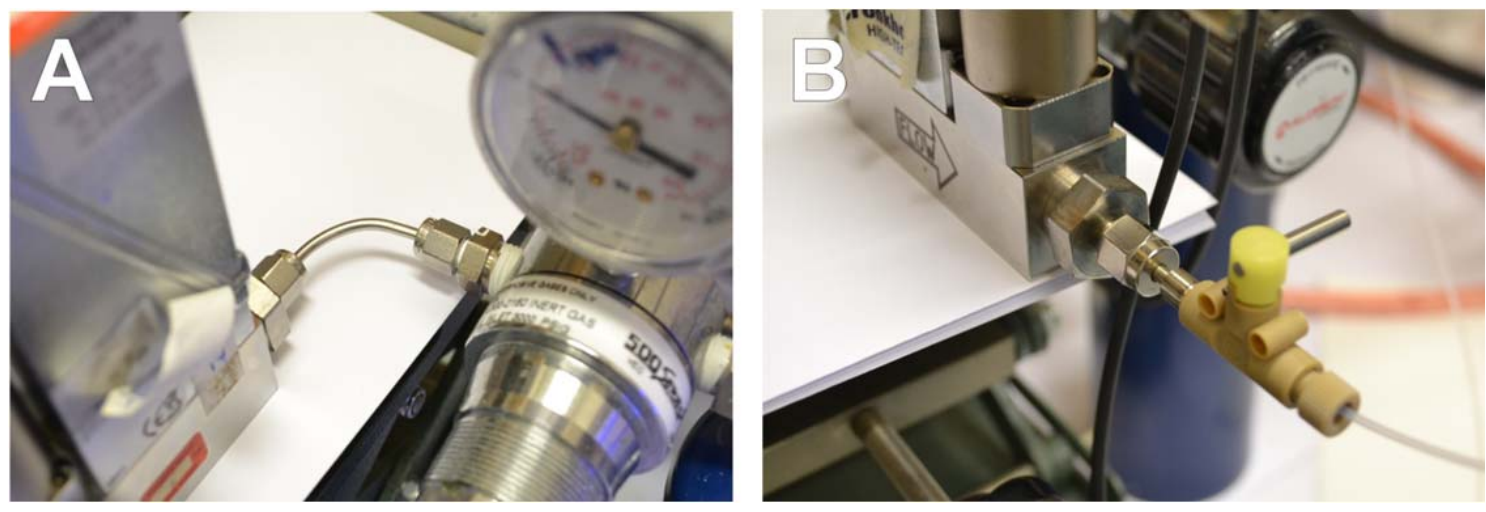

Figure 7 | (A) Connection of the MFC to the gas regulator outlet with a stainless steel tube. (B) Connection between the MFC to the PFA capillary tubing with a $1 / 8^{\prime \prime}$ to $1 / 16^{\prime \prime}$ adapter and a PEEK 
union. Note the PEEK shut valve, which can be closed to prevent liquid entering the MFC due to back flow.

5 | Cut several pieces of PFA capillary tubing $\left(1 / 16^{\prime \prime}, I D=0.5 \mathrm{~mm}\right)$ at a length of 50 $\mathrm{cm}$ and connect the ends of the tubing with PEEK nuts and ETFE ferrules (Figure 8). Note, these capillaries are used to establish connections; such as, connections between syringe pumps and the photomicroreactor.

6 | Position a PEEK cross micromixer $(1 / 16 ", I D=0.5 \mathrm{~mm})$ in a central place inside the fume hood and fixate with a clamp.

7| Connect the photomicroreactor with the PEEK cross micromixer using a capillary prepared in step 5.

8| Position and fixate the photomicroreactor in the fume hood using a clamp. $<$ CRITICAL STEP $>$ It is crucial that the photomicroreactor is kept in a stable position to maintain a steady flow regime inside the photomicroreactor.

9 1 Connect an inlet check valve to the PEEK cross micromixer opposite to the connection of the photomicroreactor (Figures $9 \mathrm{~A}$ and $9 \mathrm{~B}$ ); this is the gas inlet. <CRITICAL STEP > The use of check valves (also known as a no-return valve or one-way valve) prevents the back flow of liquid reaction streams to the mass flow controller, which can damage the correct working of the MFC.

10 Connect the stainless steel tube adaptor (step 3) and the check valve with a PFA capillary prepared in step 5. Use a PEEK shut-off valve to establish a connection between the stainless steel tube adaptor and the PFA capillary (Figure 7B). $<$ CRITICAL STEP> When the photomicroreactor is clogged, back flow of the liquid stream might occur despite the use of a check valve. The shutoff valve can be used to prevent the liquid stream to enter the MFC. 
11 Connect two PFA capillaries (step 5) with the remaining inlets of the PEEK cross micromixer (Figure 9). Connect the other end with a PEEK quick connect Luer adapter. These adapters are used to connect syringes, containing the substrate and catalyst solution, to the microreactor assembly (Figure 11C).
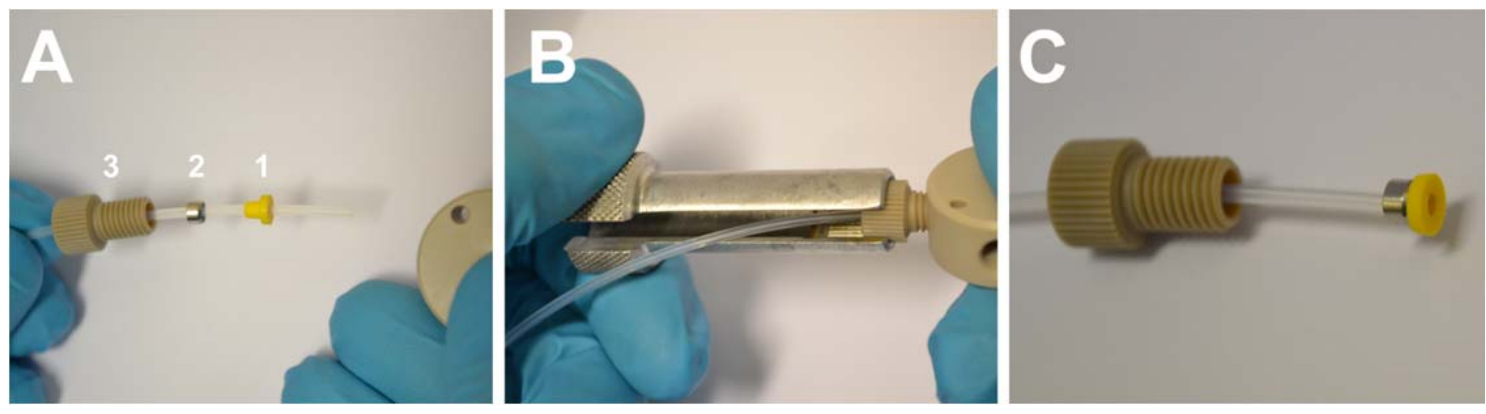

Figure 8 | (A) Assembly of the PFA capillary tubing with PEEK nuts and ETFE ferrules. (B) Tightening the connection with an extender torque wrench. (C) Final nut/ferule assembly. Note that the tubing end is flat and aligned with the yellow ferrule. The stainless steel rings must be pushed completely over the ETFE ferrules to avoid leakages. The coned end of the stainless steel ring must point towards the yellow ETFE ferrule.
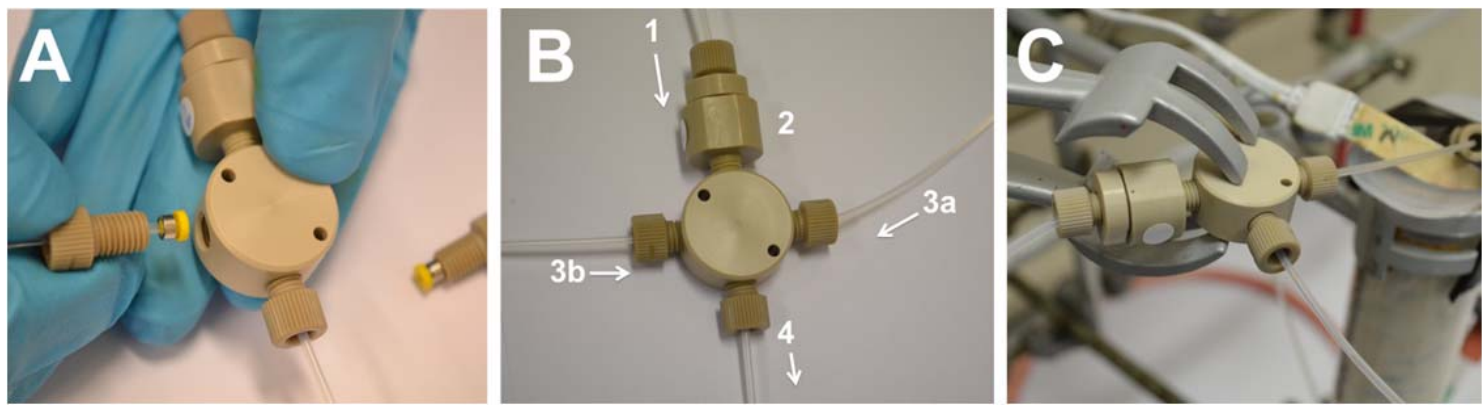

Figure 9 | (A and B) Connect the different microfluidic connections to the cross micromixer: Gas inlet (1) with check valve (2), liquid stream inlets (3) and the outlet toward the photomicroreactor (4) (Note: the arrows show the correct flow direction). (C) Final assembly of the cross micromixer and photomicroreactor mounted inside the fume hood and fixated with a clamp.

12 The outlet of the reactor can be done in three different ways depending on the application (Figure 10): 
(12-a) Standard outlet: Fit the outlet of the photomicroreactor with a PEEK Union and connect with another piece of PFA tubing (step 5), leading to the collection vial. <TROUBLESHOOTING>

(12-b) Product dilution: Fit the outlet of the photomicroreactor with a PEEK tee micromixer and connect with another piece of PFA tubing (step 5), leading to the collection vial. Fit the other inlet of the tee micromixer with a piece of PFA tubing (step 5). Connect the other end of this capillary with a PEEK quick connect Luer adapter so it can be connected to a $10 \mathrm{~mL}$ syringe containing a suitable dilution solvent (e.g. MeCN). <TROUBLESHOOTING>

(12-c) - Reaction mixture quenching: Similar to step 12-b but with a syringe containing a saturated mixture of $\mathrm{NH}_{4} \mathrm{Cl}$ in $\mathrm{H}_{2} \mathrm{O}$ which is used to quench the reaction mixture. <TROUBLESHOOTING>

13 Keep the collection vial under an argon atmosphere. <CRITICAL STEP> This is especially important for the photocatalytic aerobic oxidation of thiols as the reaction proceeds slowly in the presence of oxygen, which might lead to seemingly unreproducible results.

14 | Connect a rubber hose to the nozzle of the photomicroreactor assembly to supply pressurized air from a compressor. This ensures adequate cooling of the photomicroreactor to keep the reaction temperature at room temperature.

15 | Connect the LED array to the LED power supply.

16 | Check all PEEK connections for leakage by running the entire setup with pure solvent. In addition, check the system sealing via the soap bubble technique. <TROUBLESHOOTING>

<PAUSE POINT> The entire photomicroreactor setup is now completed and ready for use in photocatalytic experiments. 


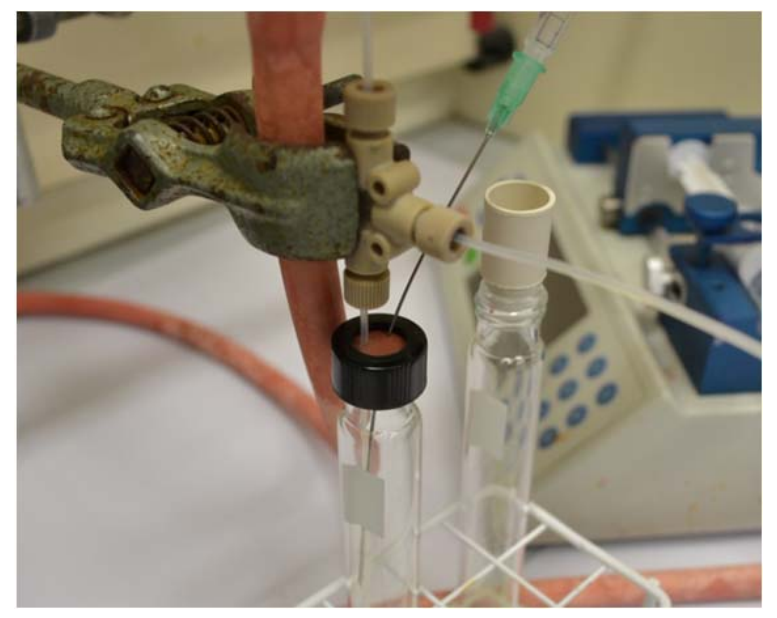

Figure 10 | Example of a reactor exit and reaction mixture collection. A PEEK tee micromixer is used to dilute or quench the reaction stream exiting the photomicroreactor.

Glassware. All reaction glassware was thoroughly cleaned and dried in the oven at $110^{\circ} \mathrm{C}$ overnight prior to use. The glassware was allowed to cool to room temperature before use in a desiccator.

NMR. Chemical shifts for ${ }^{1} \mathrm{H}$ NMR spectra are reported relative to the TMS $(0.0 \mathrm{ppm})$ or residual solvent peak, for ${ }^{13} \mathrm{C}$ NMR spectra relative to chloroform (77.13 ppm) and for ${ }^{19} \mathrm{~F}$ NMR spectra relative to $\alpha, \alpha, \alpha$-trifluorotoluene (-73.62 ppm). 


\section{PROCEDURE}

Table 1 | Overview of all the starting materials used in this protocol, the obtained yield range (as the average of three independent flow experiments), the flow rates of the liquid stream $\left(Q_{L}\right.$ in $\left.\mathrm{mL} \mathrm{min}^{-1}\right)$ and gas stream, $\left(Q_{G}\right.$ in $\left.\mathrm{mL} \mathrm{min}^{-1}\right)$ (the values indicate the setting on the syringe pumps and the MFC), total flow rate inside the photomicroreactor $\left(Q_{T}\right.$ in $\left.\mathrm{mL} \mathrm{min}^{-1}\right)$ and residence time $\left(T_{R}\right)$.

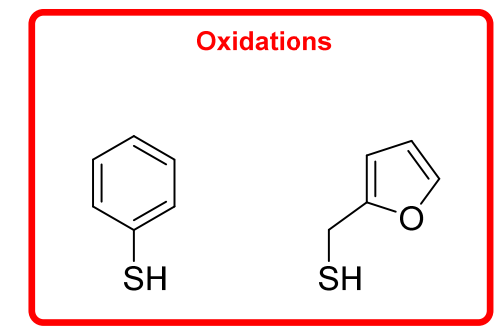

$98-100 \%$ yield $\quad 83-87 \%$ yield

$Q_{\mathrm{L} 1}=0.058$

$Q_{L 2}=0.058$

$Q_{G}=0.350$

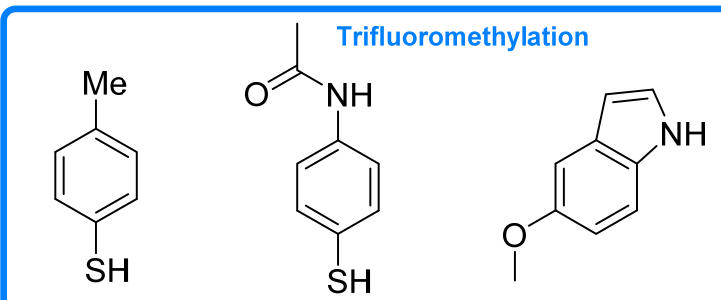

$92-95 \%$ yield

$96-98 \%$ yield

$75-77 \%$ yield
$69-73 \%$ yield

$\begin{array}{llll}Q_{\mathrm{L} 1}=0.40 & Q_{\mathrm{L} 1}=0.05 & Q_{\mathrm{L} 1}=0.05 & Q_{\mathrm{L} 1}=0.025 \\ \mathrm{Q}_{\mathrm{L} 2}=0.40 & \mathrm{Q}_{\mathrm{L} 2}=0.05 & \mathrm{Q}_{\mathrm{L} 2}=0.05 & \mathrm{Q}_{\mathrm{L} 2}=0.025 \\ \mathrm{Q}_{\mathrm{G}}=2.000^{\mathrm{a}} & \mathrm{Q}_{\mathrm{G}}=1.500^{\mathrm{a}} & \mathrm{Q}_{\mathrm{G}}=1.500^{\mathrm{a}} & \mathrm{Q}_{\mathrm{G}}=1.000^{\mathrm{a}}\end{array}$

$Q_{T}=0.466$

$\mathrm{Q}_{\mathrm{T}}=0.054$

$\mathrm{Q}_{\mathrm{T}}=0.84$

$\mathrm{Q}_{\mathrm{T}}=0.13$

$\mathrm{Q}_{\mathrm{T}}=0.13$

$Q_{T}=0.07$

$\mathrm{T}_{\mathrm{R}}=2.4 \mathrm{~min}$

$$
\mathrm{T}_{\mathrm{R}}=20 \mathrm{~min}
$$

$\mathrm{T}_{\mathrm{R}}=0.92 \mathrm{~min}$

$\mathrm{T}_{\mathrm{R}}=8.5 \mathrm{~min}$

$\mathrm{T}_{\mathrm{R}}=8.5 \mathrm{~min}$

$T_{R}=15.7 \mathrm{~min}$

\begin{tabular}{|c|c|c|c|c|c|}
\hline $\begin{array}{l}\text { Light source: } \\
\text { White LED }\end{array}$ & $\begin{array}{l}\text { Light source: } \\
\text { White LED }\end{array}$ & $\begin{array}{l}\text { Light source: } \\
\text { Blue LED }\end{array}$ & $\begin{array}{l}\text { Light source: } \\
\text { Blue LED }\end{array}$ & $\begin{array}{l}\text { Light source: } \\
\text { Blue LED }\end{array}$ & $\begin{array}{l}\text { Light source: } \\
\text { Blue LED }\end{array}$ \\
\hline $\begin{array}{l}\text { Diluted at exit: } \\
\mathrm{EtOH} / \mathrm{NH}_{4} \mathrm{Cl}\end{array}$ & $\begin{array}{l}\text { Diluted at exit: } \\
\text { EtOH } / \mathrm{NH}_{4} \mathrm{Cl}\end{array}$ & $\begin{array}{l}\text { Diluted at exit: } \\
\text { - }\end{array}$ & $\begin{array}{l}\text { Diluted at exit: } \\
\text { MeCN }\end{array}$ & $\begin{array}{l}\text { Diluted at exit: } \\
\text { - }\end{array}$ & $\begin{array}{l}\text { Diluted at exit } \\
\text { MeCN }\end{array}$ \\
\hline
\end{tabular}

${ }^{a}$ Trifluoroiodomethane has a higher solubility than oxygen in the solvent; therefore, the gas flow rates of trifluoroiodomethane are much higher than those of oxygen. $\mathrm{NH}_{4} \mathrm{Cl}=$ Saturated ammonium chloride in $\mathrm{H}_{2} \mathrm{O}$. 
The photocatalytic aerobic oxidation of thiols to disulfides in continuous microflow $<T\|M\| N G> \pm 4$ hours

1 Add Eosin $Y(0.25 \mathrm{mmol})$ and TMEDA (25 mmol) to an oven-dried $50 \mathrm{~mL}$ volumetric flask and fill up with ethanol to $50 \mathrm{~mL}$ (solution 1-A).

2 Add thiol (25 mmol, consult Table 1) to a second oven-dried $50 \mathrm{~mL}$ volumetric flask and fill up with ethanol to $50 \mathrm{~mL}$ (solution 1-B).

3 Transfer the substrate and catalyst solution from the flasks to syringes (syringes 1-A and 1-B, respectively).

4 I Prepare two other syringes $(50 \mathrm{~mL})$ with $\mathrm{EtOH}$ and saturated $\mathrm{NH}_{4} \mathrm{Cl}$ in $\mathrm{H}_{2} \mathrm{O}$, (syringes 1-C and 1-D, respectively).

5 Mount the syringes (1-A and 1-B) containing the catalyst and substrate solutions on a first syringe pump (Fusion 200 Classic). Fit these two syringes to the PFA tubing by means of PEEK quick connect Luer adapters leading to the cross micromixer.

6 | Mount syringes (1-C and 1-D) containing the quench and extraction solutions on a second syringe pump (Fusion 200 Classic). Fit these two syringes to the PFA tubing by means of the PEEK quick connect Luer adapters at the quenching zone.

7 | Turn on the LED light source.

8| Open the pressurized air supply to cool the photomicroreactor <CRITICAL STEP> This step keeps the photomicroreactor system at room temperature $\left(22 \pm 1^{\circ} \mathrm{C}\right)$, which can be optionally monitored by a thermocouple.

9 I Open the oxygen gas supply, pressure regulator and set the MFC $\left(Q_{G}\right.$, Table 1). <CRITICAL STEP> The MFC should be stabilized for at least one hour prior to use. This can be done before you prepare the reactant solutions. 
10 Turn on the syringe pumps and set the correct volumetric flow rates $\left(Q_{L}\right.$, Table 1) which correspond to a certain flow rate and residence time $\left(Q_{T}\right.$ and $R_{T}$, Table 1). Allow the system to reach steady state.

11 Collect the reaction stream exiting the photomicroreactor in a flask $(50 \mathrm{~mL})$. $<$ CRITICAL STEP $>$ Enough time should be taken to ensure a steady state data collection. For example, steady state conditions for sampling can be ensured after about 4 residence times. The system stability can be checked by careful observation of the hydrodynamics within certain sections of the capillary microreactor in the system (e.g. entrance and exit). In other words, the segmented gas-liquid flow should be stable, meaning that the slug lengths and the gas/liquid ratio should be constant. The total collection time depends on the volumetric flow rate of substrate solution. <TROUBLE SHOOTING>

12 Stop the two syringe pumps.

13 | Replace the four syringes by four new syringes with cleaning solvents (e.g. ethanol), and then run these two syringe pumps again in order to clean the photomicroreactor system. <CRITICAL STEP> This step is necessary to prevent precipitation of catalyst or product which will lead to microreactor clogging. <TROUBLE SHOOTING>

14 Stop the mass flow controller and switch off the LED light source and close the cooling air supply in order to shut down the entire microfluidic setup.

15 Dilute the collected reaction mixture with $15 \mathrm{~mL}$ EtOAc and extract twice with $15 \mathrm{~mL} 1 \mathrm{M} \mathrm{HCl}$. Wash the organic phase once with $15 \mathrm{~mL}$ of saturated aq. $\mathrm{NaHCO}_{3}$

16 Collect the combined organic layers and concentrate under reduced pressure in a rotary evaporator. <CRITICAL STEP> If the products are volatile, it is 
recommended to use $\mathrm{Et}_{2} \mathrm{O}$ (bp $34.6^{\circ} \mathrm{C}$ at atmospheric pressure) instead of EtOAc (bp $77.0^{\circ} \mathrm{C}$ at atmospheric pressure).

17 | Purify the crude product by flash column chromatography $(20 \mathrm{~cm}$ Silica, $\varnothing$ column $=2.5 \mathrm{~cm}$, see details in anticipated results section).

18 Collect the combined fractions containing pure product and concentrate under reduced pressure to yield the desired product (Table 1). <TROUBLE SHOOTING>
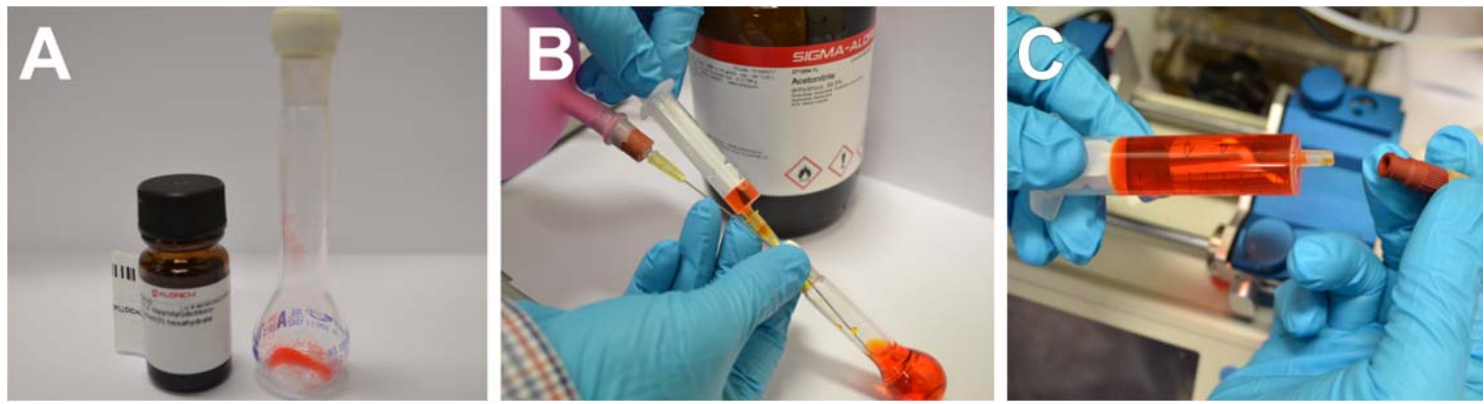

Figure 11 | Example of the preparation of a reaction solution (here, $\mathrm{Ru}(\mathrm{bpy}){ }_{3} \mathrm{Cl}_{2} 6 \mathrm{H}_{2} \mathrm{O}$ in $\left.\mathrm{MeCN}\right)(\mathrm{A})$, transferring to syringe (B) and connecting to the microfluidic system (C). Note the absence of bubbles inside the syringe. 
The photocatalytic trifluoromethylation of heterocycles and thiols with $\mathrm{CF}_{3} \mathrm{I}$ in continuous microflow $<T\|M\| N G> \pm 6$ hours

19 Add heterocycle or thiol $(5.0 \mathrm{mmol})$ and TMEDA or TEA (10 mmol) to an ovendried $10 \mathrm{~mL}$ volumetric flask and fill up with anhydrous acetonitrile to $10 \mathrm{~mL}$. Seal the flask with a rubber septum and purge with argon (solution 2-A).

20 Add $\mathrm{Ru}(\mathrm{bpy})_{3} \mathrm{Cl}_{2} 6 \mathrm{H}_{2} \mathrm{O}(37.5 \mathrm{mg}, 0.05 \mathrm{mmol}, 1 \mathrm{~mol} \%$ ) to a second oven-dried $10 \mathrm{~mL}$ volumetric flask and fill up anhydrous acetonitrile to $10 \mathrm{~mL}$. Seal the flask with a rubber septum and purge with argon (solution 2-B) (Figure 11A for solution 2-B).

<PAUSE POINT> The solutions (2-A and 2-B) can be stored for several days in the dark in the refrigerator.

21 Transfer both solutions from the flasks to disposable syringes (syringes 2-A and 2-B, respectively) (Figure 11B).

22 Mount the syringes (2-A and 2-B) onto the syringe pump (Fusion 200 Classic) and connect these two syringes to the PFA tubing by means of the PEEK quick connect Luer adapters at the cross micromixer (Figure 11C).

23 Turn on the LED light source.

24 I Open the pressurized air supply to cool the photomicroreactor <CRITICAL STEP> This step keeps the photomicroreactor system at room temperature $\left(22 \pm 1^{\circ} \mathrm{C}\right)$, which can be optionally monitored by a thermocouple.

25 I Open the trifluoroiodomethane gas bottle and set the gas pressure regulator to 4-5 Bar. Set the MFC to the correct value ( $Q_{G}$, Table 1). <CRITICAL STEP> It is important to open the trifluoroiodomethane gas bottle completely, the MFC requires a high inlet pressure to work correctly. <TROUBLE SHOOTING> 
26 | Turn on the syringe pump and set the correct volumetric flow rate $\left(Q_{L}\right.$, Table 1) which correspond to a certain flow rate and residence time $\left(Q_{T}\right.$ and $R_{T}$, Table 1). Allow the system to reach steady state. <TROUBLE SHOOTING>

27 | Collect the reaction stream exiting the photomicroreactor in a flask $(50 \mathrm{~mL})$. $<$ CRITICAL STEP $>$ Enough time should be taken to ensure a steady state data collection. For example, steady state conditions for sampling can be ensured after about 4 residence times. The system stability can be checked by careful observation of the hydrodynamics within certain sections of the capillary microreactor in the system (e.g. entrance and exit). In other words, the segmented gas-liquid flow should be stable, meaning that the slug lengths and the gas/liquid ratio should be constant. The total collection time depends on the volumetric flow rate of substrate solution. <TROUBLE SHOOTING>

28 Stop the syringe pump

29 | Replace the four syringes by four new syringes with cleaning solvents (e.g. ethanol), and then run these two syringe pumps again in order to clean the photomicroreactor system. <CRITICAL STEP> This step is necessary to prevent precipitation of catalyst or product which will lead to microreactor clogging.

30 Stop the mass flow controller and switch off the LED light source and close the cooling air supply in order to shut down the entire microfluidic setup.

31 | Disconnect the MFC and purge with argon for at least 1 hour. $\angle$ CRITICAL STEP> This is to prevent swelling of the MFC sealings.

32 I Dilute the collected reaction mixture with $15 \mathrm{~mL}$ EtOAc and extract twice with $15 \mathrm{~mL} 1 \mathrm{M} \mathrm{HCl}$. Wash the organic phase once with $15 \mathrm{~mL}$ of sat. aq. $\mathrm{NaHCO}_{3}$. 
33 Collect the combined organic layers and concentrate under reduced pressure in a rotary evaporator. <CRITICAL STEP> If the products are volatile, it is recommended to use $\mathrm{Et}_{2} \mathrm{O}$ (bp $34.6^{\circ} \mathrm{C}$ at atmospheric pressure) instead of EtOAc (bp $77.0^{\circ} \mathrm{C}$ at atmospheric pressure).

34 I Purify the crude product by flash column chromatography $(50 \mathrm{~cm}$ Silica, $\varnothing$ column $=2.5 \mathrm{~cm}$, see details in anticipated results section).

35 Collect the combined fractions containing pure product and concentrate under reduced pressure to yield the desired product (Table 1). <TROUBLE SHOOTING>

\section{TIMING}

Steps 1-2, Preparation of the reagents/catalyst solution and the starting material solution: $\sim 15$ min per sample

Step 3-6, Transferring the solutions into syringes and mounting them on the syringe pumps: $\sim 10 \mathrm{~min}$

Steps $7-10$, Start-up procedure of the microfluidic setup (reaching steady state of gas and liquid flows): 2-30 min (residence time dependent, about four residence times is required to reach a steady state)

Step 11, Collecting reaction mixture: 10 minutes to 2 hours (residence time + reaction scale dependent)

Steps 12-14, Cleaning and shutting down microfluidic setup: 15 min

Steps 15-16, Extracting reaction mixture: $30 \mathrm{~min}$

Steps 17-18, Purification of crude mixture with column chromatography: 1 hour 
Steps 19-20, Preparation of the Reagents/Catalyst solution and the starting material solution: $\sim 15$ min per sample

Steps 21-22, transferring the solutions into syringes and mounting them on the syringe pumps: $\sim 5 \mathrm{~min}$

Steps 23-26, Start-up procedure of the microfluidic setup (reaching steady state of gas and liquid flows): 2-30 min (residence time dependent, about four residence times is required to reach a steady state)

Step 27, Collecting reaction mixture: 10 minutes to 2 hours (residence time + reaction scale dependent)

Step 28-31, Cleaning and shutting down microfluidic setup: 15 min

Step 33-33, Extracting reaction mixture: $30 \mathrm{~min}$

Step 34-35, Purification of crude mixture with column chromatography: 1 hour 


\section{TROUBLESHOOTING}

\section{Troubleshooting advice can be found in Table 2 .}

Table 2 | Troubleshooting.

\begin{tabular}{lll} 
Step & Problem & Possible reason \\
\hline 4 (Box 2) & Gas Leakage & $\begin{array}{l}\text { Damaged or worn } \\
\text { connection parts. }\end{array}$ \\
$\mathbf{1 2}$ (Box 2) & $\begin{array}{l}\text { Which outlet strategy } \\
\text { should one choose? }\end{array}$ & $\begin{array}{l}\text { Different substrate from } \\
\text { protocol }\end{array}$
\end{tabular}

16 (Box 2) Liquid leakage

11

13

The PFA capillary is blocked.

The reproducibility of experiments in terms of isolated yield is low.

The collecting time is insufficient and thus the sample size is too low leading to larger experimental errors.

Precipitation inside the PFA tubing.

\section{Solution}

Use Teflon tape to get a tighter fit between the connecting parts.

Replace damaged parts.

Use option 11-B to prevent possible precipitation due to evaporation at the outlet of the microreactor.

Use an extender torque wrench to tighten the connection.

Replace damaged parts.

Collect sample for a sufficient amount of time. As a rule of thumb, $1 \mathrm{mmol}$ scale experiments and more are reproducible.

This often occurs in the startup phase or when the microreactor is stored without cleaning. Once the reaction reaches steady state, no clogging was observed.

Wash the capillary with a suitable solvent which can solubilize the precipitation (acetone and water).

It is of high importance that clogging is detected at the early stages to be able to remediate the situation.

If irreversible blockage occurs, replace the tubing.

Decrease the liquid and gas flow rate to extend the 
residence time.

\begin{tabular}{|c|c|c|c|}
\hline \multirow[t]{2}{*}{25} & $\begin{array}{l}\text { Desired pressure is } \\
\text { not reached. }\end{array}$ & $\begin{array}{l}\text { Gas bottle and } \\
\text { pressure regulator are } \\
\text { not opened enough }\end{array}$ & $\begin{array}{l}\text { Open the gas bottle and } \\
\text { make sure the pressure } \\
\text { regulator is functioning } \\
\text { accordingly. }\end{array}$ \\
\hline & & Gas bottle is empty & $\begin{array}{l}\text { Check pressure regulator } \\
\text { and if required connect a } \\
\text { new gas cylinder }\end{array}$ \\
\hline
\end{tabular}
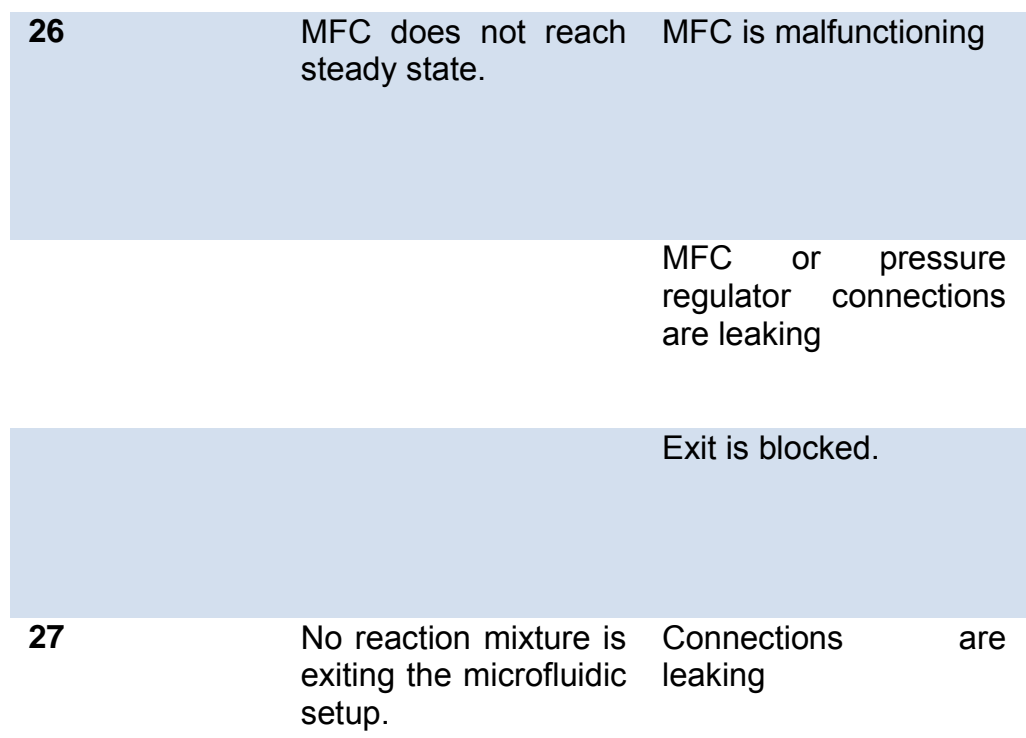

Exit is blocked.

Connections leaking setup.
Clean the MFC with acetone and purge the MFC with argon at a flowrate of $1 \mathrm{~mL} \mathrm{min-1}$ overnight.

Check for leaks, use Teflon tape to get a tighter fit between the connection parts

Pre-test your gas regulation system prior to connecting the rest of the microfluidic setup.

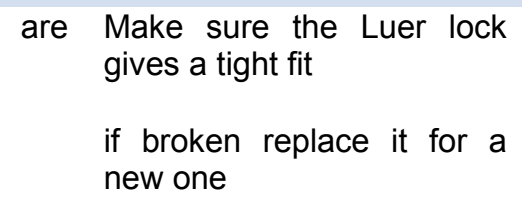
new one

$\begin{aligned} & \text { Syringe is leaking } \\ & \text { (rare) }\end{aligned}$
Photomicroreactor is
blocked - particle
formation at the start or
middle of the reactor

Photomicroreactor is blocked - particle formation at the end of the reactor Remove blockage as
mentioned above.

\section{Remove blockage; use a solvent stream to dilute the reaction mixture after the reactor. \\ Make sure the reactor is clean and that possible solvent inside is miscible with the reaction mixture}

Photomicroreactor is
blocked - unsteady
flow rate.

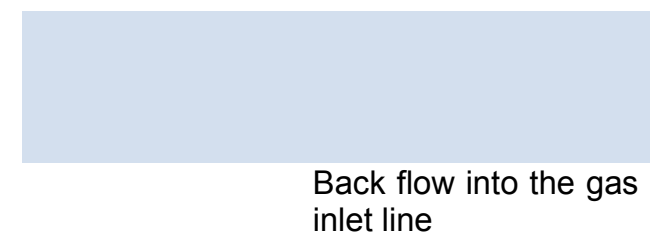




\begin{tabular}{|c|c|c|c|}
\hline & & gas flowrate & pressure regulator \\
\hline & & $\begin{array}{l}\text { Photomicroreactor is } \\
\text { blocked - other } \\
\text { reasons }\end{array}$ & $\begin{array}{l}\text { Use a PFA capillary of } 250 \\
\mu m \text { for the gas line. This } \\
\text { ensures a high pressure } \\
\text { drop for liquid back flow. }\end{array}$ \\
\hline & $\begin{array}{l}\text { Back flow into the } \\
\text { liquid inlet lines }\end{array}$ & $\begin{array}{l}\text { Photomicroreactor is } \\
\text { blocked }- \text { leaking } \\
\text { syringes }\end{array}$ & $\begin{array}{l}\text { Remove blockage; replace } \\
\text { syringes (or use a smaller } \\
\text { diameter syringe. }\end{array}$ \\
\hline \multirow[t]{3}{*}{35} & Low yield & $\begin{array}{l}\text { Residence time is too } \\
\text { short }\end{array}$ & $\begin{array}{l}\text { Decrease the liquid and } \\
\text { gas flow rate. }\end{array}$ \\
\hline & & $\begin{array}{l}\text { The gas concentration } \\
\text { is too low }\end{array}$ & Increase the gas flow rate \\
\hline & Poor selectivity & $\begin{array}{l}\text { Residence time is too } \\
\text { long }\end{array}$ & $\begin{array}{l}\text { Increase the liquid and gas } \\
\text { flow rate accordingly. }\end{array}$ \\
\hline
\end{tabular}




\section{ANTICIPATED RESULTS}

\section{Diphenyldisulfide (1-A):}

Yield: $98-100 \%$ white solid. TLC: $\left(1: 40\right.$, EtOAc:PE, v/v): $\mathbf{R}_{f}=0.31-0.35 .{ }^{1} \mathbf{H} \mathbf{N M R}$ $\left(399 \mathrm{MHz}, \mathrm{CDCl}_{3}\right): \delta 7.48(\mathrm{td}, \mathrm{J}=1.3,7.5 \mathrm{~Hz}, 4 \mathrm{H}), 7.28(\mathrm{tt}, \mathrm{J}=1.3,7.5 \mathrm{~Hz}, 4 \mathrm{H}), 7.21$ $(\mathrm{tt}, \mathrm{J}=1.3,7.5 \mathrm{~Hz}, 2 \mathrm{H}) \mathrm{ppm} .{ }^{13} \mathrm{C}$ NMR $\left(100 \mathrm{MHz}, \mathrm{CDCl}_{3}\right): \delta 127.4,127.7,129.3$, 137.2 ppm. IR (ATR, $\left.\mathrm{cm}^{-1}\right):$ 2955, 2920, 2853, 1574, 1474, 1458, 1437, 1020, 735, 685. Mp.: 58.9-59.3 ${ }^{\circ} \mathrm{C}$. GCMS (35 eV, relative intensity, m/z): $218.1\left[\mathrm{M}^{+}\right], 109.1$ $\left[\mathrm{C}_{6} \mathrm{H}_{5} \mathrm{~S}\right], 77.0[\mathrm{C} 6 \mathrm{H} 5]$.

\section{1,2-bis(furan-2-ylmethyl)disulfane (1-B):}

Yield: $84-87 \%$ transparent oil. TLC: $\left(1: 40\right.$, EtOAc:PE, v/v): $R_{f}=0.29-0.33 .{ }^{1} \mathbf{H}$ NMR (399 MHz, $\left.\mathrm{CDCl}_{3}\right): \delta 7.40(\mathrm{dd}, \mathrm{J}=0.9,1.9 \mathrm{~Hz}, 2 \mathrm{H}), 6.35(\mathrm{dd}, \mathrm{J}=1.9,3.3 \mathrm{~Hz}, 2 \mathrm{H})$, $6.24(\mathrm{~d}, \mathrm{~J}=3.3 \mathrm{~Hz}, 2 \mathrm{H}), 3.70(\mathrm{~s}, 4 \mathrm{H}) \mathrm{ppm} .{ }^{13} \mathrm{C}$ NMR (100 MHz, $\left.\mathrm{CDCl}_{3}\right): \delta$ 35.7, 109.1, 110.9, 142.6, 150.3 ppm. IR (ATR, $\mathrm{cm}^{-1}$ ): 1500, 1238, 1148, 1121, 1069, 1009, 934, 808, 727, 708. GCMS (35 eV, m/z): $226.2\left[\mathrm{M}^{+}\right], 161.2,81.1\left[\mathrm{C}_{5} \mathrm{H}_{5} \mathrm{O}\right]$, 53.1.

\section{(4-methylphenyl)(trifluoromethyl)sulfane (3-B)}

Yield: $92-95 \%$ Volatile liquid (determined by ${ }^{19} \mathrm{~F}$ NMR, GC-MS). TLC: (Solvent, Rf): (100, PE, v/v): 0.82. ${ }^{1} \mathrm{H}$ NMR: $\left(399 \mathrm{MHz}, \mathrm{CDCl}_{3}\right) 7.52(\mathrm{~d}, \mathrm{~J}=7.9 \mathrm{~Hz}, 1 \mathrm{H}), 7.19(\mathrm{~d}, \mathrm{~J}=$ $7.9 \mathrm{~Hz}, 1 \mathrm{H}), 2.36$ (s, 3H). ${ }^{13} \mathrm{C}$ NMR: $\left(100 \mathrm{MHz}, \mathrm{CDCl}_{3}\right) \delta 141.52,136.50,130.37$, 129.85 (q, J = 307.6 Hz), 121.02 (q, J = 1.9 Hz), 21.35. ${ }^{19}$ F NMR: (377 MHz, CDCI3): ס -44.76. GCMS: (35 eV, m/z): $192.1\left[\mathrm{M}^{+}\right], 91.0\left[\mathrm{C}_{7} \mathrm{H}_{7} \mathrm{~S}\right], 76.1\left[\mathrm{C}_{6} \mathrm{H}_{4}\right], 69.1\left[\mathrm{CF}_{3}\right]$. 


\section{N-(4-(trifluoromethylthio)phenyl)acetamide (4-B)}

Yield: $95-98 \%$ off-white solid. TLC: (Solvent, Rf): (10:90, $\left.\mathrm{Et}_{2} \mathrm{O}: \mathrm{PE}, \mathrm{v} / \mathrm{v}\right):$ 0.25-0.29, (20:80, Et2O:PE, v/v): 0.35-0.37. ${ }^{1}$ H NMR: (399 MHz, DMSO): $\delta 10.19$ (bs, 1H), 7.68 $(\mathrm{d}, \mathrm{J}=8.7 \mathrm{~Hz}, 2 \mathrm{H}), 7.56(\mathrm{~d}, \mathrm{~J}=8.7 \mathrm{~Hz}, 2 \mathrm{H}), 2.03(\mathrm{~s}, 3 \mathrm{H}) .{ }^{13} \mathrm{C}$ NMR: $(100 \mathrm{MHz}$, DMSO): $\delta 168.82,142.25,137.17,129.53$ (q, J = 308.2 Hz), $119.72,115.52$, 109.54. ${ }^{19}$ F NMR: (377 MHz, DMSO): $\delta$-42.99. IR: (neat, $\left.\mathrm{cm}^{-1}\right): 1665,1650,1607$, 1589, 1492, 1468, 1399, 1372, 1317, 1298, 1262, 1183, 1119, 1107, 1088, 1040, 1014, 968, 960, 949, 836, 827, 796, 761, 753, 716, 706. GCMS (35 eV, m/z): 235.4 $\left[\mathrm{M}^{+}\right], 166.1\left[\mathrm{C}_{8} \mathrm{H}_{8} \mathrm{NOS}\right], 134.1\left[\mathrm{C}_{8} \mathrm{H}_{8} \mathrm{NO}\right], 69.1\left[\mathrm{CF}_{3}\right] \mathrm{Mp} .: 185-186{ }^{\circ} \mathrm{C}$.

\section{5-methoxy-2(trifluoromethyl)-1H-indole (5-B):}

Yield: $75-77 \%$, colourless oil. TLC: (Solvent, Rf): (10:90, $\left.\mathrm{Et}_{2} \mathrm{O}: \mathrm{PE}, \mathrm{v} / \mathrm{v}\right):$ 0.25-0.29, (20:80, Et2O:PE, v/v): 0.35-0.37. ${ }^{1}$ H NMR: (399 MHz, CDCl3) $\delta 8.04$ (s, 1H), 7.57 (d, $\mathrm{J}=7.6 \mathrm{~Hz}, 1 \mathrm{H}), 7.31(\mathrm{~d}, \mathrm{~J}=7.6 \mathrm{~Hz}, 1 \mathrm{H}), 7.24(\mathrm{t}, \mathrm{J}=7.6 \mathrm{~Hz}, 1 \mathrm{H}), 7.12(\mathrm{t}, \mathrm{J}=7.6 \mathrm{~Hz}$,

1H), 2.37 (s, 3H). ${ }^{13} \mathrm{C}$ NMR: (100 MHz, CDCl3) $\delta 135.34,128.20,124.90,123.60$, $121.68(\mathrm{~d}, \mathrm{~J}=37.2 \mathrm{~Hz}), 120.52,120.22,114.20(\mathrm{~d}, \mathrm{~J}=3.1 \mathrm{~Hz}), 111.70,29.86 .{ }^{19} \mathrm{~F}$ NMR: (377 MHz, CDCI3): $\delta$-56.74. IR: (neat, $\mathrm{cm}^{-1}$ ): 1556, 1458, 1379, 1247, 1219, 1168, 1109, 1083, 1028, 842, 798, 684. GCMS (35 eV, m/z): $215\left[\mathrm{M}^{+}\right], 200$ $\left[\mathrm{C}_{9} \mathrm{H}_{5} \mathrm{~F}_{3} \mathrm{NO}\right], 172,152$.

\section{methyl 5-(trifluoromethyl)-1H-pyrrole-2-carboxylate (6-B):}

Yield: $69-73 \%$ white solid. TLC: (Solvent, Rf): (10:90, $\left.\mathrm{Et}_{2} \mathrm{O}: \mathrm{PE}, \mathrm{v} / \mathrm{v}\right): 0.25-0.27$, (20:80, Et2O:PE, v/v): 0.45-0.5. ${ }^{1}$ H NMR: (399 MHz, CDCl3): $\delta 9.97$ (s, 1H), 6.81 (s,

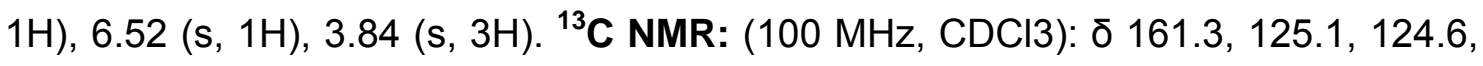

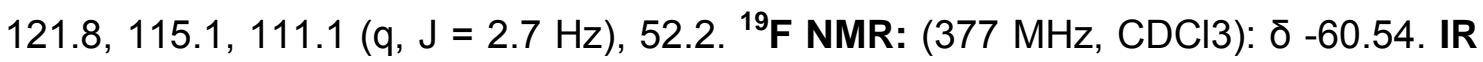


(neat, $\left.\mathrm{cm}^{-1}\right): 1697,1440,1280,1259,1155,1103,993,804,763,736$. HRMS (ESI): calculated $\left(\mathrm{C}_{7} \mathrm{H}_{6} \mathrm{~F}_{3} \mathrm{NO}_{2}-\mathrm{H}^{+}\right):$192.0272; found: 192.0272. GCMS (35 eV, m/z): 193 $\left[\mathrm{M}^{+}\right], 178\left[\mathrm{C}_{6} \mathrm{H}_{3} \mathrm{~F}_{3} \mathrm{NO}_{2}\right], 162\left[\mathrm{C}_{6} \mathrm{H}_{3} \mathrm{~F}_{3} \mathrm{NO}\right], 69.1$ [CF 3$] . \mathrm{Mp} .: 152-153^{\circ} \mathrm{C}$.

\section{ACKNOWLEDGEMENTS}

Y.S. would like to thank the European Union for a Marie Curie - Intra-European Fellowship (No 622415). T.N. would like to acknowledge financial support from the Dutch Science Foundation (NWO) for a VENI Grant (No 12464) and from the European Union for a Marie Curie CIG Grant (Flach). Funding by the Advanced European Research Council (Grant number: 267443 for V.H.) is kindly acknowledged. T.N. would like to thank all M.Sc. and B.Sc. students that have worked on this topic in the past years for their efforts.

\section{AUTHOR CONTRIBUTIONS}

N.J.W.S. and Y.S. carried out the experiments and designed the protocol. N.J.W.S. and T.N. developed the visible light photocatalytic transformations. Y.S., V.H. and T.N. developed the final photomicroreactor design. T.N. designed and supervised the project. All authors contributed in the writing of the manuscript.

\section{COMPETING FINANCIAL INTERESTS}

The authors declare no competing financial interests.

\section{REFERENCES}


1. Prier, C. K., Rankic, D. A. \& MacMillan, D. W. C. Visible light photoredox catalysis with transition metal complexes: Applications in organic synthesis. Chem. Rev. 113, 5322-5363 (2013).

2. Fukuzumi, S. \& Ohkubo, K. Organic synthetic transformations using organic dyes as photoredox catalysts. Org. Biomol. Chem. 12, 6059-6071 (2014).

3. Hari, D. P. \& König, B. Synthetic applications of eosin $Y$ in photoredox catalysis. Chem. Commun. 50, 6688-6699 (2014).

4. Cassano, A. E., Martin, C. A., Brandi, R. J. \& Alfano O. M. Photoreactor analysis and design: fundamentals and applications. Ind. Eng. Chem. Res. 34, 2155-2201 (1995).

5. Ghafoori, S., Mehrvar, M. \& Chan, P.K., Photoreactor scale-up for degradation of aqueous poly(vinyl alcohol) using $\mathrm{UV} / \mathrm{H}_{2} \mathrm{O}_{2}$ process. Chem. Eng. J. 245, 133-142 (2014).

6. Hartman, R. L., McMullen, J. P. \& Jensen, K. F. Deciding whether to go with the flow: evaluating the merits of flow reactors for synthesis. Angew. Chem. Int. Ed. 50, 7502-7519 (2011).

7. McQuade, D. T. \& Seeberger, P. H. Applying flow chemistry: methods, materials, and multistep synthesis. J. Org. Chem. 78, 6384-6389 (2013).

8. Su, Y., Straathof, N. J. W., Hessel, V. \& Noël, T. Photochemical transformations accelerated in continuous-flow reactors: Basic concepts and applications. Chem. Eur. J. 20, 10562-10589 (2014).

9. Garlets, Z. J., Nguyen, J. D. \& Stephenson, C. R. J. The development of visible light photoredox catalysis in flow. Isr. J. Chem. 54, 351-360 (2014).

10. Kashid, M. N., Renken, A. \& Kiwi-Minsker L. Gas-liquid and liquid-liquid mass transfer in microstructured reactors. Chem. Eng. Sci. 66, 3876-3897 (2011). 
11. Günther, A. \& Jensen, K. F. Multiphase microfluidics: from flow characteristics to chemical and materials synthesis. Lab Chip 6, 1487-1503 (2006).

12. Angeli, P. \& Gavriilidis, A. Hydrodynamics of Taylor flow in small channels: A Review. Proc. Inst. Mech. Eng. C- J. Mech. Eng. Sci. 222, 737-751 (2008).

13. Li, W., et al. Microfluidic study of fast gas-liquid reactions. J. Am. Chem. Soc. 134, 3127-3132 (2012).

14. Straathof, N. J. W. et al. Rapid trifluoromethylation and perfluoroalkylation of five-membered heterocycles by photoredox catalysis in continuous flow. ChemSusChem 7, 1612-1617 (2014).

15. Straathof, N. J. W. et al. Visible light photocatalytic metal-free perfluoroalkylation of heteroarenes in continuous flow. J. Flow Chem. 4, 12-17 (2014).

16. Straathof, N. J. W., Tegelbeckers, B. J. P., Hessel, V., Wang, X. \& Noël, T. A mild and fast photocatalytic trifluoromethylation of thiols in batch and continuous flow. Chem. Sci. 5, 4768-4773 (2014).

17. Talla, A. et al. Metal-free photocatalytic aerobic oxidation of thiols to disulfides in batch and continuous flow. Adv. Synth. Catal. DOI: 10.1002/adsc.201401010 (2015).

18. Su, Y., Hessel, V. \& Noël, T. A compact photomicroreactor design for kinetic studies of gas-liquid photocatalytic transformations. AIChE J. DOI: 10.1002/aic.14813 (2015).

19. Maskill, K. G., Knowles, J. P., Elliott, L. D., Alder, R. W. \& Booker-Milburn, K. I. Complexity from simplicity: Tricyclic aziridines from the rearrangement of pyrroles by batch and flow photochemistry. Angew. Chem. Int. Ed. 52, 14991502 (2013). 
20.Zhang, Y., Blackman, M. L., Leduc, A. B. \& Jamison, T. F. Peptide Fragment Coupling Using a Continuous-Flow Photochemical Rearrangement of Nitrones. Angew. Chem. Int. Ed. 52, 4251-4255 (2013).

21. Yue, J., Chen, G. Yuan, Q., Luo, L. \& Gonthier, Y. Hydrodynamics and mass transfer characteristics in gas-liquid flow through a rectangular microchannel. Chem. Eng. Sci. 62, 2096-2108 (2007).

22. Trachsel, F., Günther, A., Khan, S. \& Jensen, K. F. Measurement of residence time distribution in microfluidic systems. Chem. Eng. Sci. 60, 57295737 (2005). 